\title{
Otolith-check formation and accelerated growth associated with sex change in an annual protogynous tropical fish
}

\author{
Stefan P. W. Walker*, Mark I. McCormick \\ School of Marine Biology and Aquaculture, James Cook University, Townsville, Queensland 4811, Australia
}

\begin{abstract}
Growth of the haremic sandperch Parapercis cylindrica (family Pinguipedidae) was examined in relation to sex change using otolith microstructure and gonad histology. The influence of previous growth history on the timing of sex change and which individuals underwent sex change were also explored. Examination of otolith increments shows that $P$. cylindrica has a maximum longevity of $411 \mathrm{~d}$, which is reduced in a lower latitude population. P. cylindrica is a monandric hermaphrodite, with males being larger than females at any given age. An abrupt optical discontinuity or 'check' on sagittal cross-sections was found to be associated with sex change. This check appears to be formed at the initiation of sex change. Growth rate following sex change, inferred from otolith increment widths, increased markedly and more than doubled in some individuals. Individuals retained accelerated growth for a period of up to $30 \mathrm{~d}$, after which time growth rate declined. Larval growth, relative size at metamorphosis, juvenile growth, and female growth (all determined from otolith microstructure), did not influence which individuals changed sex, or the timing of their sex change. Evidence suggests that sex change and subsequent growth acceleration in these haremic fish are influenced by the strong size-based social hierarchy in which they live.
\end{abstract}

KEY WORDS: Sex change - Monandric protogyny · Growth acceleration · Otolith increments · Larval growth $\cdot$ Pinguipedidae

\section{INTRODUCTION}

Many coral reef fishes maintain polygamous mating systems, whereby a few large males can monopolize mating through resource- or female-defence. In these species, the net fitness returns from energy allocated to somatic growth are greater for males than for females, and as a consequence males are almost invariably larger than females (Ghiselin 1969, Warner 1984). However, the majority of polygamous reef fishes are protogynous hermaphrodites. Individuals first mature as females and later change sex to become males; this optimises lifetime fitness, since small males have low reproductive success (Ghiselin 1969, Warner 1984, 1988). The interrelationship between energy allocation in the different sex states, growth and the control of sex change is central to understanding the evolu- tion and maintenance of sexual dimorphism in sexchanging fishes.

To explain sex-specific size-at-age differences in protogynous species, 2 proximate hypotheses have been suggested. The first is the 'transitional growthspurt hypothesis' (Ross 1987, Garratt et al. 1993, Choat et al. 1996), whereby somatic growth is accelerated during sex change, resulting in larger males (1 in Fig. 1). The second hypothesis, the 'juvenile growth hypothesis', states that sex-specific size-at-age differences are the result of growth trajectories established early in life (Francis \& Barlow 1993, Adams \& Williams 2001) (2 in Fig. 1). This hypothesis predicts that females with the fastest growth rates have the highest probability of changing sex. There is also a third possible hypothesis that is yet to be explored, which may be termed the 'larval growth hypothesis'. It is plausible 
that enhanced larval growth may bias post-settlement growth, influence the timing of maturation and subsequently determine which individuals undergo sex change (3 in Fig. 1). Recent studies of fishes have also shown that fast growth during early larval life can enhance survival well into the juvenile stage (Vigliola \& Meekan 2002). Given the advantages of large size in the social systems formed by demersal fishes (Werner \& Gilliam 1984), it is likely that growth advantages initiated in a fish's early life history may lead to growth and maturational advantages later in life.

To date, no studies have examined the relative importance of these non-exclusive growth hypotheses. To do so, it is necessary to track the growth of individuals through time in relation to the timing of settlement, female maturation and sex change. Fortunately, daily and annual increments in fish otoliths provide a chronological record of past growth, and may be used in conjunction with histological examination of gonad development to address the interrelationship of growth and the timing of life-history transitions. Otolith growth may be used as proxy for somatic growth once increment periodicity has been validated and a proportional otolith-somatic relationship independent of somatic growth rate has been established (Hare \& Cowen 1995, Campana 2001). Otoliths can also store information about the timing of key life-history events, such as settlement and possibly sex change. Abrupt discontinuities or 'checks' in the otolith microstructure are associated with settlement from the larval phase to the reef population (Wilson \& McCormick 1997, 1999), and checks due to abrupt shifts in feeding regimes, light, and temperature, have also been reported (Eckmann \& Rey 1987). Check marks may also be formed during sex change, given the dramatic shifts in physiology and

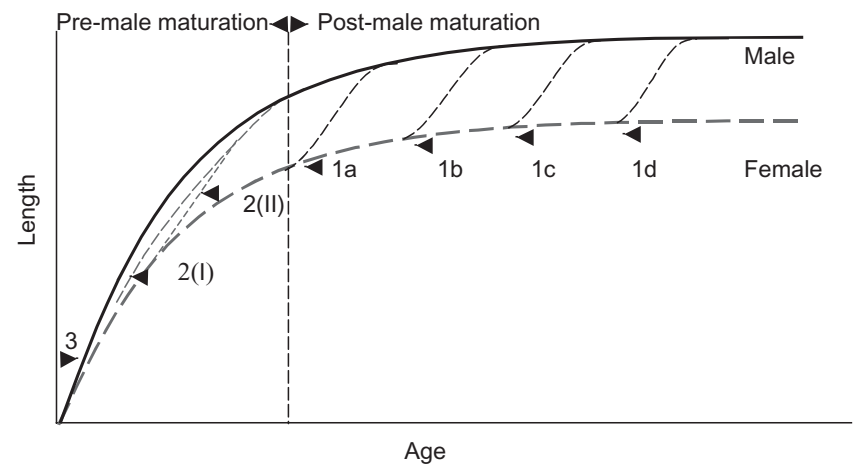

Fig. 1. Potential sex-specific growth divergence pathways in protogynous species. Males may be larger than females of same age because: (1) growth acceleration occurs following sex change (may occur between ages a to d), (2) fast-growing juveniles (I) or females (II) have an increased likelihood of changing sex; (3) pre-settlement history influences growth and likelihood of sex change. Unbroken line: male growth; dashed lines: female growth behaviour associated with this life-history transition (Warner 1984, Devlin \& Nagahama 2002). The discovery of a check mark associated with sex change would enable the relative importance of the 3 growth hypotheses to be addressed, and greatly enhance our understanding of the mechanisms underlying sex change and sexual size-dimorphism in fishes.

The aims of the present study were to establish whether daily increments on otoliths may be used as a proxy for age-based somatic growth in the short-lived protogynous sandperch Parapercis cylindrica (family Pinguipedidae), and to examine the relationship between growth history and sex change. By linking the reproductive biology of individuals to their growth histories, we were able to examine whether there is an irregularity or check in the otolith associated with sex change. This allowed us to explore whether the age or relative size at sex change was related to larval, juvenile or female growth history. This study is the first to clearly demonstrate a strong temporal link between sex change from female to male and accelerated growth in an annual species.

\section{MATERIALS AND METHODS}

The species. Parapercis cylindrica is a common inhabitant of shallow-water rubble and sand substratum on coral reefs of the Indo-Pacific, with a distribution that spans the Western Pacific, east to Fiji and the Marshall Islands (Randall et al. 1997). Detailed behavioural observations have shown that $P$. cylindrica forms harems containing 2 to 10 females and 1 male. Females are strongly site-attached and territorial, while males have a home range that encompasses all the territories of the females within his harem (Stroud 1982, S. Walker unpubl. data). Both males and females are very aggressive towards sexual conspecifics, and males spend a considerable amount of time in border protection and female peace-keeping, particularly during the spawning period (S. Walker unpubl. data). At Orpheus Island and Lizard Island, Great Barrier Reef (GBR), Australia, spawning occurs daily and year-round. Each day a male pair-spawns in the water column with each female within his harem during the hour prior to nightfall (Stroud 1982). By comparing temporal patterns in spawning with patterns of recruitment, Stroud (1982) estimated that the pelagic larval duration of $P$. cylindrica was approximately $30 \mathrm{~d}$.

Sampling protocol. Individuals were collected from 2 locations within the GBR, separated by $6^{\circ}$ of latitude. During December 2001, 70 individuals were collected from the leeward fringing reef of Orpheus Island $\left(18^{\circ} 36^{\prime} \mathrm{S}, 146^{\circ} 28^{\prime} \mathrm{E}\right)$. During March 2002, 100 individuals were collected from the lagoon of One Tree Island reef $\left(24^{\circ} 30^{\prime} \mathrm{S}, 152^{\circ} 10^{\prime} \mathrm{E}\right)$. 
Fish were captured using a drop net and a solution of anaesthetic clove oil, and immediately killed by cold shock. Total length $(\mathrm{TL} \pm 0.1 \mathrm{~mm})$ and total fish wet weight ( $F W \pm 0.0001 \mathrm{~g}$ ) was recorded for each individual. The sagittal otoliths were then removed, cleaned of endolymph tissue, and stored dry prior to processing for age determination. Gonads were removed and stored in a formalin-acetic acid-calcium chloride solution (Winsor 1994) for $1 \mathrm{wk}$ prior to histological processing.

Histology and diagnosis of gonads. Gonads were weighed $( \pm 0.0001 \mathrm{~g})$ and embedded in paraffin-wax blocks. Four $5 \mu \mathrm{m}$ sections were taken from each gonad and stained with Myer's haematoxylin and Young's eosin-erythrosin (Winsor 1994). These sections were examined under a compound microscope and individuals were categorised as juveniles, females, sex-changing transitionals, or males, based on the presence of characteristic sex-cells (Sadovy \& Shapiro 1987, Devlin \& Nagahama 2002). The gonads of transitional individuals contained an ovarian lumen, degenerating oocytes, testicular tissue and spermatocytes (Sadovy \& Shapiro 1987). Males were further classified into 4 groups ranked on the percentage of crosssection area occupied by the former ovarian lumen: $\geq 10,5-9,1-4$ and $0 \%$. These ranks follow the chronological sequence of sex change (Sadovy \& Shapiro 1987). The presence or absence of mature spermatozoa was also noted for each rank. Gender-specific gonadosomatic indices (GSI = [gonad weight/total body weight] $\times 100$ ) were calculated for both locations and analyzed by a 2-way factor analysis of variance $(\alpha=$ 0.05). Assumptions of homogeneity of variance and normality were tested by residual analysis (Zar 1999). Post hoc comparisons were performed using Tukey's HSD test for unequal sample sizes.

Validation of increment periodicity. To evaluate the periodicity of otolith-increment deposition, tetracycline tagging was employed. The smallest Parapercis cylindrica available were collected using a solution of anaesthetic clove oil and a hand net, and were brought into the Orpheus Island laboratory where they were immersed in an aerated solution of $250 \mathrm{mg} \mathrm{l}^{-1}$ tetracycline-hydrochloride (Boehringer Mannheim) in seawater for $24 \mathrm{~h}$ in the dark. Tetracycline is commonly used as a temporal tag as it leaves a mark on the otolith that is fluorescent under ultraviolet (UV) light. Once fish had been tagged with tetracycline, they were kept for $10 \mathrm{~d}$ (9 nights) in flowing seawater, after which they were killed by cold-shock. Otoliths were extracted, and kept in the dark until they were sectioned and examined under UV light. The number of days that fish were kept after tagging was compared to the number of otolith increments deposited between the fluorescent tag and outer margin of the otolith.
Otolith preparation. Sagittal otoliths were used for age determination and processing followed the methods of Wilson \& McCormick (1997). Briefly, an otolith was first fixed to the edge of a glass slide with the thermoplastic resin Crystalbond ${ }^{\mathrm{TM}}$ so that the distal end of the otolith extended over the edge of the slide. The otolith was orientated so that the edge of the slide ran through the distal outer margin of the nucleus and the distal-rostral plane was perpendicular to the edge of the slide. The otolith was then ground to the edge of the slide using 400 to 1200 grade wet and dry sandpaper, and then polished with 12 to $3 \mu \mathrm{m}$-grade lapping film. The resin was then reheated and the otolith orientated polished-face-down on the surface of the slide. The rostral end of the otolith was ground down to the rostral margin of the nucleus and polished as above. This produced a transverse section of the sagitta displaying increments from the nucleus to the outer margin of the otolith.

Age determination and growth. Sectioned otoliths were viewed under a high-power microscope with polarised transmitted light, and the maximum otolith radius $(\mathrm{OR})$ was recorded $(\mu \mathrm{m})$. Two readers counted the number of growth increments from the nucleus to the outer margin of the otolith along the OR, and the average was used as an estimate of age. Early growth increments surrounding the nucleus were indistinct in 16 otoliths from Orpheus Island and 23 otoliths from One Tree Island. In these cases, the average number of increments deposited within the indistinct zone was extrapolated from a mean relationship between increment number and OR.

The relationships between growth dimensions (TL, FW, OR) and age were described using standard regression analysis in order to (1) establish size-at-age relationships, (2) assess whether TL was proportional to FW, (3) assess whether otolith growth was proportional to somatic growth, and (4) determine if otolith growth explained a significant amount of variation in somatic growth, thus warranting the use of otolith dimensions as a proxy for somatic growth. A significance level of 0.01 was used as the criterion for evaluating the significance of regression coefficients (Shea 1985). Variation in the regression models between sexes and locations was determined by analysis of covariance $(\alpha=0.05)$.

The robustness of otolith-somatic scaling to variation in growth rate was evaluated following the procedure of Hare \& Cowen (1995). Linear regression models were used to describe the relationship of OR and age with TL. Heteroscedasticity was reduced by lntransformation of independent and dependent variables. Residuals from the relationships between ln OR on ln TL (otolith-somatic scaling) and ln age on ln TL (growth rate) were then compared using Pearson's 
correlation. If the relationship between otolith and somatic growth is unaffected by growth rate, then the standardized residuals from the 2 models should display no correlation.

Growth divergence and sex change. A subsample of 7 males and 5 of the oldest females was used for increment-width analysis to generate individual growth profiles. Increment widths were measured in microns from digital frames at $400 \times$ magnification using the software package OPTIMAS. This was carried out to ascertain the age at which sex-specific growth divergence occurred.

Detailed examination of the transverse sections of the sagittae revealed check marks in the microstructure of male otoliths represented by changes in the optical density of the increments. These checks closely corresponded to the approximate time of growth divergence between sexes. To investigate whether these check marks corresponded to abrupt changes in otolith growth, otolith increment widths before and after the check marks were compared. This 'transition-centred' method (Wilson \& McCormick 1997) allows the significance of growth transitions to be analysed with greater clarity than the averaged increment profiles, which mask these events since they occur at slightly different times for each individual. Mean increment width before and after the otolith check mark were compared by a repeatedmeasures analysis of variance $(\alpha=0.05)$. The assumption of compound symmetry was tested using Mauchly's test of sphericity (Zar 1999).

As a preliminary validation of the association between the check mark and time of sex change, the time since formation of the check mark (number of days from otolith margin to check mark) was correlated with the index of male gonad state (described above) using Spearman's correlation for rank data (S). Male gonad condition was ranked into 4 categories based on the size of the former ovarian lumen, which is largest in transitional individuals and completely absent in fully mature males.

Sex change and early life-history traits. To investigate whether early life-history traits influenced which individuals changed sex or age at sex change, larval, juvenile, and female growth (inferred from otolith increment width) was compared between mature females and males, and related to the age (in days) of sex change within the male population. In all individuals, an obvious check on the otolith (Type Ia, Wilson \& McCormick 1999) was found at approximately the same number of increments from the nucleus as previous estimates of larval duration had suggested ( 30 d: Stroud 1982). The linear distance from the nucleus to this settlement check along the main cross-sectional axis of the sagitta was used as an estimate of relative body size at settlement (SAS). The number of increments between the nucleus and settlement check was used as an estimate of pelagic larval duration (PLD), and average larval growth rate (LGR) was calculated as SAS divided by PLD. Similarly, average juvenile growth rate (JGR) was calculated as the distance between the settlement mark and the otolith increment associated with the minimum age of female maturity (100 d, inferred from histological examination of the gonads), and average female growth rate (FGR) was calculated as the distance between the $100 \mathrm{~d}$ otolith increment and the otolith increment associated with the minimum age of sex change (150 d, inferred from histological examination of the gonads). Males were subsampled randomly, however only females older than the average age at sex change were used to draw these comparisons, so that their gender was not specifically related to age. PLD, LGR, SAS, JGR and FGR were compared between females and males by analysis of variance $(\alpha=$ 0.05). Assumptions of homogeneity of variance and normality were tested by residual analysis (Zar 1999). The relationship of these measures to the age at sex change within the male population, inferred from the sex-associated check mark, was examined using a step-wise multiple regression. The assumption of linearity was visually checked prior to analysis.

\section{RESULTS}

\section{Gonadosomatic index}

GSI differed statistically between locations $\left(F_{1,140}=\right.$ $6.1, \mathrm{p}=0.015)$, sexes $\left(F_{3,140}=35.26, \mathrm{p}=0.0001\right)$, and location by $\operatorname{sex}\left(F_{3,140}=10.94, \mathrm{p}=0.0001\right)$. Both females and males from Orpheus Island had larger GSI values than fish from One Tree Island. Mature females had the highest GSIs (Orpheus Island $=3.14 \pm 0.20 \%$, One Tree Island $=1.89 \pm 0.3 \%$ ), which were an order of magnitude higher than those of males (Orpheus Island $=0.31 \pm 0.02 \%$, One Tree Island $=0.09 \pm 0.01 \%$ ). Juvenile, transitional and male GSIs were statistically similar within locations.

\section{Validation of increment periodicity}

The otoliths from all fish immersed in tetracycline had a distinct fluorescent mark interior to the otolith margin when viewed under UV light. The fluorescent mark coincided with a microstructural discontinuity (check), which could be viewed under polarised transmitted light. Regular increments on the sagittal otoliths were validated as being daily. The average number of increments deposited within 
the $10 \mathrm{~d}$ trial period was $9.8 \pm 0.489 \mathrm{SE}(\mathrm{n}=5)$ : the magnitude of the error was determined by 2 otoliths in which disruption of the microstructure was severe and identification of the first increment following the tetracycline tag was unclear. The remaining 3 otoliths deposited 10 clear increments during the trial period. The error rate associated with the 2 otolith increment counts was low $( \pm 3.7 \%$ coefficient of variation, CV).

\section{Otolith-somatic scaling}

A strong positive relationship was found between otolith growth and somatic growth. The relationship between OR and TL was best explained by a linear model (Table 1), where OR explained $91 \%$ of the variation in TL for the Orpheus Island population ( $p=0.0001)$, and $94 \%$ of TL in the One Tree Island population $(p=0.0001)$. No difference was found in the relationship between populations (Table 1).

The relationship between otolith and somatic growth was consistent for varying rates of growth. No correlation was found between the standardized residuals from the relationship between $\ln$ OR and $\ln \mathrm{TL}$, and the standardized residuals of somatic growth rate (ln age on $\ln \mathrm{TL}$ ) (Orpheus Island: $\mathrm{r}=0.16, \mathrm{p}=0.002$; One Tree Island: $r=0.07, p=0.012$ ) (Fig. 2). Therefore, growth rate had no significant effect on otolith-somatic scaling. These results suggest that otolith growth increments may be used as an age-based proxy for somatic growth in Parapercis cylindrica.

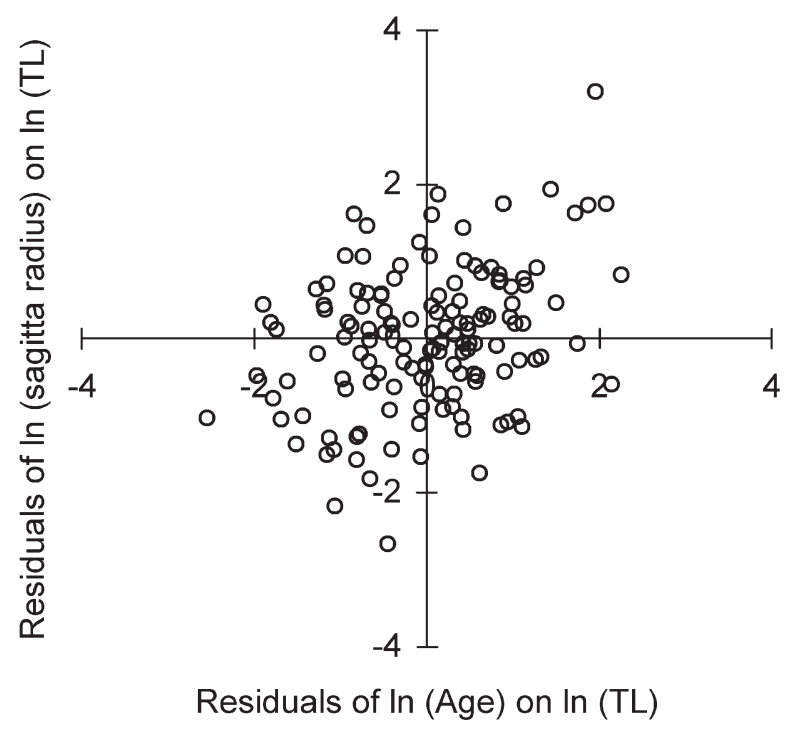

Fig. 2. Parapercis cylindrica. Pooled data from Orpheus Island and One Tree Island populations showing relationship between standardised residuals from a regression of otolith radius or versus total length, TL (both log-transformed) and standardized residuals of a regression of TL versus age (both log-transformed)

\section{Size-at-age relationships}

TL was proportional to FW in both populations $(\mathrm{r}=$ 0.99, $\mathrm{p}=0.0001$ ), where the relationships were best described by power curves (Table 1). Intercepts differed between populations (Table 1). Fish from One Tree Island attain a greater FW per TL than fish from Orpheus Island.

Table 1. Parapercis cylindrica. Relationships between growth dimensions: total length (TL), fish wet weight (FW), otolith radius (OR) and age. Regression of TL-at-age described by von Bertalanffy growth equation $L_{t}=L_{\infty}\left(-\mathrm{e}^{-K\left(t-t_{0}\right)}\right)$ where $L_{t}$ is mean length at age $t_{1} L_{\infty}$ is asymptotic mean length, and $t_{0}$ (length at Age 0) is constrained to 0. OI: Orpheus Island; TI: One Tree Island; lower-case superscripts denote significant post hoc differences (Tukey's HSD for unequal replication). $W_{\text {interaction }}$ : Wald statistic for ANCOVA of power curves. All scaling $=p<0.001$

\begin{tabular}{|c|c|c|c|c|c|c|}
\hline $\begin{array}{l}\text { Growth } \\
\text { dimensions }\end{array}$ & Sex & $\mathrm{n}$ & Model & $r^{2}$ & $\begin{array}{l}\text { Covariance } \\
F\end{array}$ & $\mathrm{p}$ \\
\hline FW $(\mathrm{g})$ on TL $(\mathrm{mm})$ & $\begin{array}{l}\text { Pooled (OI) } \\
\text { Pooled (TI) }\end{array}$ & $\begin{array}{l}70 \\
81\end{array}$ & $\begin{array}{l}\mathrm{FW}=3.0 \mathrm{E}^{-6}(\mathrm{TL})^{3.27} \\
\mathrm{FW}=8.0 \mathrm{E}^{-6}(\mathrm{TL})^{3.07}\end{array}$ & $\begin{array}{l}0.99 \\
0.99\end{array}$ & $W_{\text {interaction }}=22.30$ & 0.000 \\
\hline OR $(\mu \mathrm{m})$ on TL $(\mathrm{mm})$ & $\begin{array}{l}\text { Pooled (OI) } \\
\text { Pooled (TI) }\end{array}$ & $\begin{array}{l}70 \\
81\end{array}$ & $\begin{array}{l}\mathrm{OR}=6.96(\mathrm{TL})+93.19 \\
\mathrm{OR}=6.56(\mathrm{TL})+154.45\end{array}$ & $\begin{array}{l}0.83 \\
0.87\end{array}$ & $F_{1,150}=1.44$ & 0.231 \\
\hline OR $(\mu \mathrm{m})$ on age $(d)$ & $\begin{array}{l}\text { Pooled (OI) } \\
\text { Pooled (TI) }\end{array}$ & $\begin{array}{l}70 \\
81\end{array}$ & $\begin{array}{l}\mathrm{OR}=2.15(\text { age })+344.68 \\
\mathrm{OR}=1.93(\text { age })+267.54\end{array}$ & $\begin{array}{l}0.77 \\
0.77\end{array}$ & $F_{1,150}=84.94$ & 0.000 \\
\hline FW $(g)$ on age $(d)$ & $\begin{array}{l}\text { Female }(\mathrm{OI})^{\mathrm{a}} \\
{\text { Female }(\mathrm{TI})^{\mathrm{b}}}^{\text {Male }(\mathrm{OI})^{\mathrm{c}}} \\
\text { Male }(\mathrm{TI})^{\mathrm{d}}\end{array}$ & $\begin{array}{l}52 \\
54 \\
18 \\
27\end{array}$ & $\begin{array}{l}F W=0.05(\text { age })-2.13 \\
F W=0.03(\text { age })-1.79 \\
F W=0.06(\text { age })-0.62 \\
F W=0.02(\text { age })+7.20\end{array}$ & $\begin{array}{l}0.69 \\
0.51 \\
0.67 \\
0.40\end{array}$ & $F_{1,150}=2748.48$ & 0.000 \\
\hline TL (mm) on age (yr) & $\begin{array}{l}\text { Female (OI) } \\
\text { Female (TI) } \\
\text { Pooled (OI) } \\
\text { Pooled (TI) }\end{array}$ & $\begin{array}{l}52 \\
54 \\
70 \\
81\end{array}$ & $\begin{array}{l}L_{t}=118.7\left(-\mathrm{e}^{-2.8\left(t-t_{0}\right)}\right) \\
L_{t}=127.6\left(-\mathrm{e}^{-1.6\left(t-t_{0}\right)}\right) \\
L_{t}=142.9\left(-\mathrm{e}^{-2.1\left(t-t_{0}\right)}\right) \\
L_{t}=144.9\left(-\mathrm{e}^{-1.4\left(t-t_{0}\right)}\right)\end{array}$ & $\begin{array}{l}0.70 \\
0.75 \\
0.81 \\
0.79\end{array}$ & & \\
\hline
\end{tabular}


The relationship between FW and age was best described by linear models, which differed between locations and with sex (Table 1). In both populations, males attained greater FW for a given age. The relationship between TL and age was best described by the von Bertalanffy growth equation $L_{t}=L_{\infty}\left(-\mathrm{e}^{-K\left(t-t_{0}\right)}\right)$ where $L_{t}$ is the mean length at age $t_{1} L_{\infty}$ is the asymptotic mean length, and $t_{0}$ (length at Age 0 ) is constrained to 0 (Table 1). The One Tree Island population had a slower growth rate and greater maximum length than the fish from Orpheus Island. The $K$ of females was $10 \%$ higher for the Orpheus Island sample than for the One Tree Island sample. This increased to a $25 \%$ difference in $K$ between samples when females and males were combined (Table 1). The growth trajectories of both populations do not reach a strict asymptote and curvature is minimal.

\section{Demography of sex change}

Parapercis cylindrica is an annual species, with between $97 \%$ (One Tree Island) to 100\% (Orpheus Island) of individuals living for less than 1 yr (Fig. 3a,b). The One Tree Island sample contained the oldest fish,
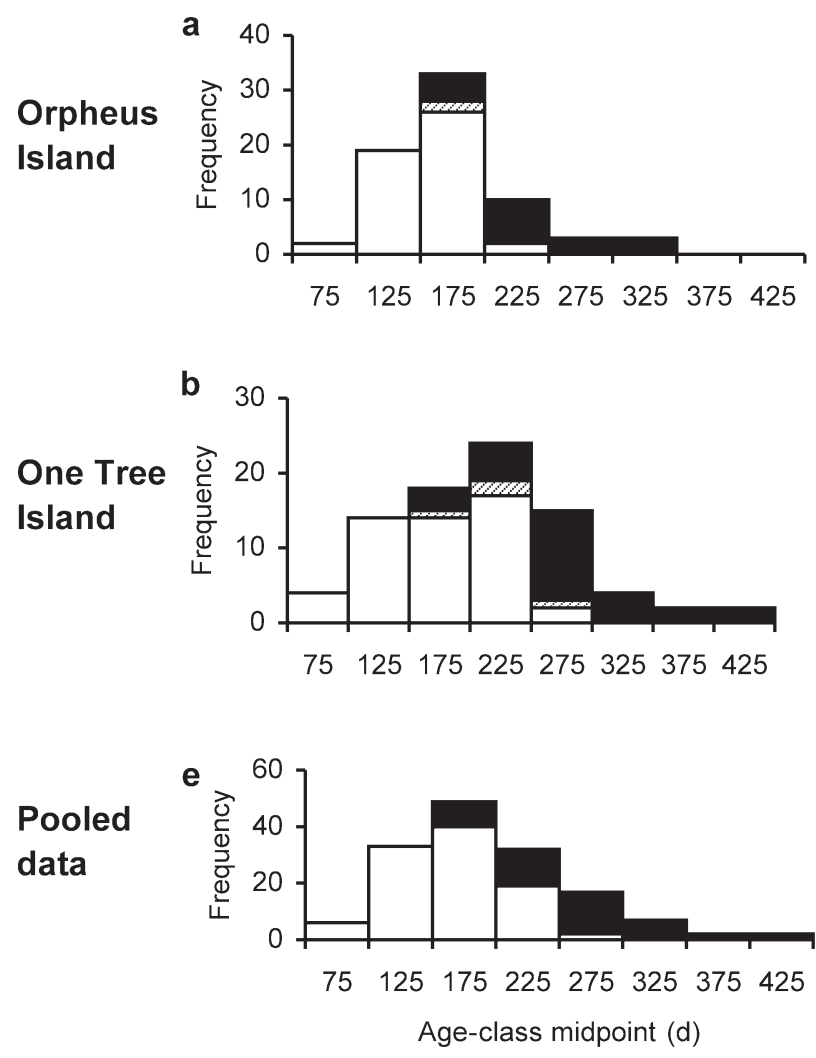

with a maximum age of $411 \mathrm{~d}$ (Fig. 3b) compared to a maximum age of $326 \mathrm{~d}$ for the Orpheus Island individuals (Fig. 3a). Older age classes consisted entirely of males in both populations (Fig. 3a,b). Age frequency distributions suggest that recruitment, and thus spawning, occurs throughout the year.

The age at which males enter the population is similar between locations, with a minimum male age of 150 d (Fig. 3a,b). Females grew older at One Tree Island than at Orpheus Island. Females at One Tree Island occurred at ages of up to $292 \mathrm{~d}$, with the modal age class for females being 200 to $250 \mathrm{~d}$ (Fig. 3b). In contrast, females from Orpheus Island only occurred up to an age of $190 \mathrm{~d}$, with the modal size range of 150 to 200 d (Fig. 3a). Transitional individuals from Orpheus Island occurred exclusively in the 150 to 200 d age-range $(n=2)$, while transitional individuals from One Tree Island spanned an age distribution of 150 to 300 d $(n=4)$. Females were mature from a size of $70 \mathrm{~mm}$ TL at both locations. Although females in the One Tree Island population reached a higher age before changing sex, the size range of sex change was similar between populations (Fig. 3c,d). All transitional fish were found within the 80 to $100 \mathrm{~mm}$ size class. There was a far greater overlap in age between females
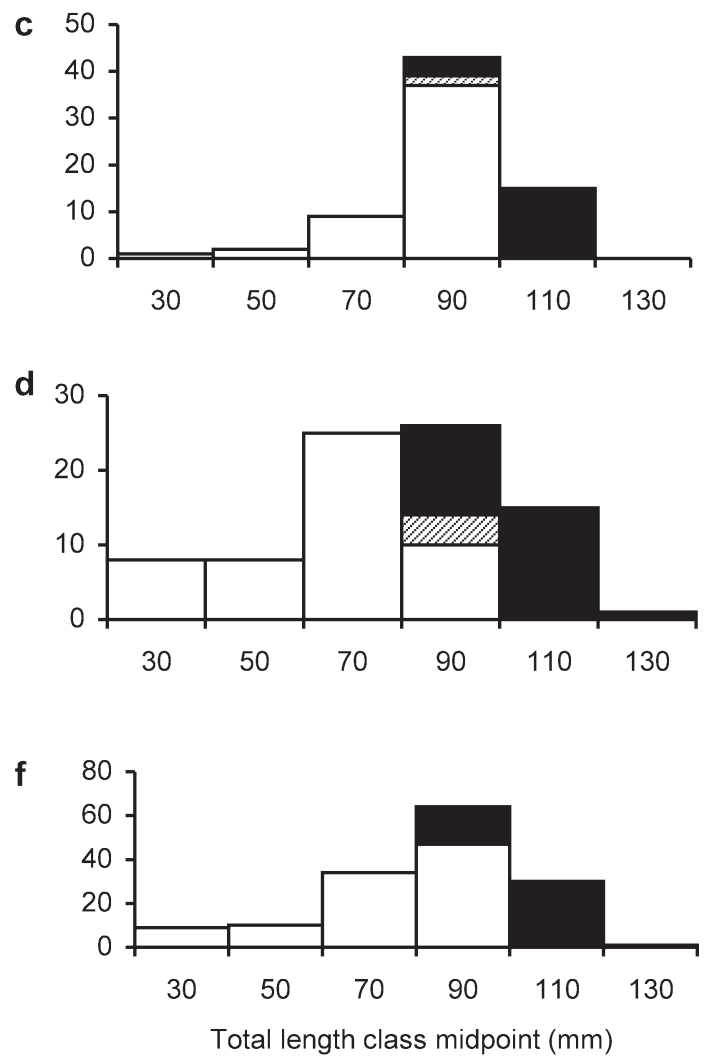

Fig. 3. Parapercis cylindrica. $(\mathrm{a}, \mathrm{b})$ Age and $(\mathrm{c}, \mathrm{d})$ total length frequency distributions by sex of specimens collected from Orpheus Island $(\mathrm{n}=70)$ and One Tree Island $(\mathrm{n}=100)$. White bars: females; hatched bars: transitionals; black bars: males. (e,f) Pooled age and total length frequency distributions 
and males than there was in size (Fig. 3). Pooled data show that females and males overlapped over an agerange of 150 to $300 \mathrm{~d}$, with the female age frequency distribution displaying a high degree of normality (Fig. 3e). In contrast, the overlap in size range for females and males was much smaller (80 to $100 \mathrm{~mm}$ ), with the female size frequency distribution being highly skewed (Fig. 3f).

\section{Growth acceleration at sex change}

Increment-width profiles, used as a measure of instantaneous growth, did not differ between females and males for the first $150 \mathrm{~d}$. After $150 \mathrm{~d}$, the growth trajectories diverged, with females otolith growth declining, while male otolith growth continued at a similar rate (Fig. 4).

Because sex change occurs at a variable age, the average otolith increment-width profiles mask the details of any changes in the growth of individuals that occurred as a result of sex change. When incrementwidth profiles of individual males are examined (Fig. 5b) the trajectories clearly show a rapid increase in growth at variable ages, but within the age-range that sex change occurred (150 to 300 d). Female trajectories showed no such increase (Fig. 5a).

A detailed examination of the otolith sections in males revealed check marks, around the time of sex change. These changes in the otolith microstructure were manifest as a change in optical density and increment width (Fig. 6). The ages at which these checks occurred corresponded closely to the interval of overlap in ages of females and males (Fig. 5). Centring the increment widths on this check mark revealed the rapid and marked change in otolith growth that occurs in the vicinity of this microstructural feature (Fig. 7). Over a $20 \mathrm{~d}$ period, mean increment width around this

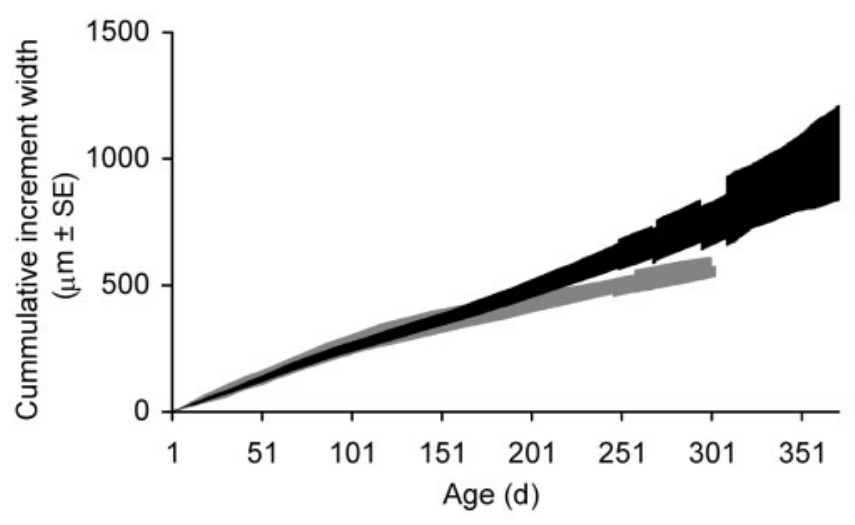

Fig. 4. Parapercis cylindrica. Cumulative increment-width profiles for females and males from One Tree Island. Grey shading: female $(n=5)$, black shading: male $(n=7)$
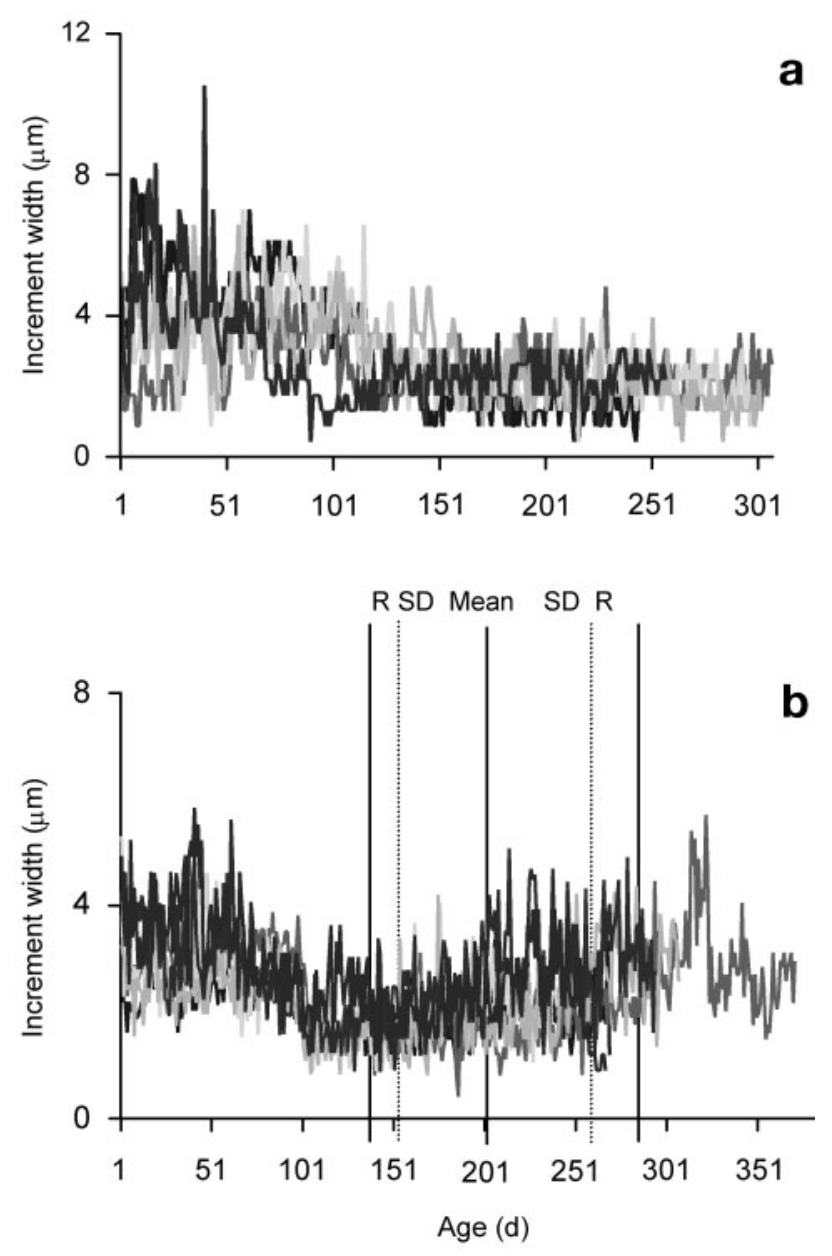

Fig. 5. Parapercis cylindrica. Increment-width profiles of (a) females ( $n=5)$ and (b) males $(n=7)$ from One Tree Island, showing range (R), standard deviation (SD), and mean age of otolith-check formation associated with sex change

check doubled from 2.1 to $4.2 \mu \mathrm{m}$ (Figs. 6b \& 7). Females showed no such increase in increment width. A repeated-measures analysis of variance revealed a significant increase in increment widths from pre- to post-check mark $\left(F_{1,154}=137.42, \mathrm{p}=0.0001\right)$.

There was a significant relationship between time since formation of a check mark (time in days between otolith margin and check mark) and the size of the former ovarian lumen $(S=0.86, p=0.0001$; see Fig. 8$)$. Time since check-mark formation increased as the size of the former ovarian lumen decreased. This result suggests that the check mark is in fact formed during the course of sex change. This is further supported by the similarity between the age-at-check-mark frequency distribution and the male population age frequency distribution (Fig. 9). The presence of a time lag between the 2 distributions further suggests that the check mark is formed at the initiation of sex change. 


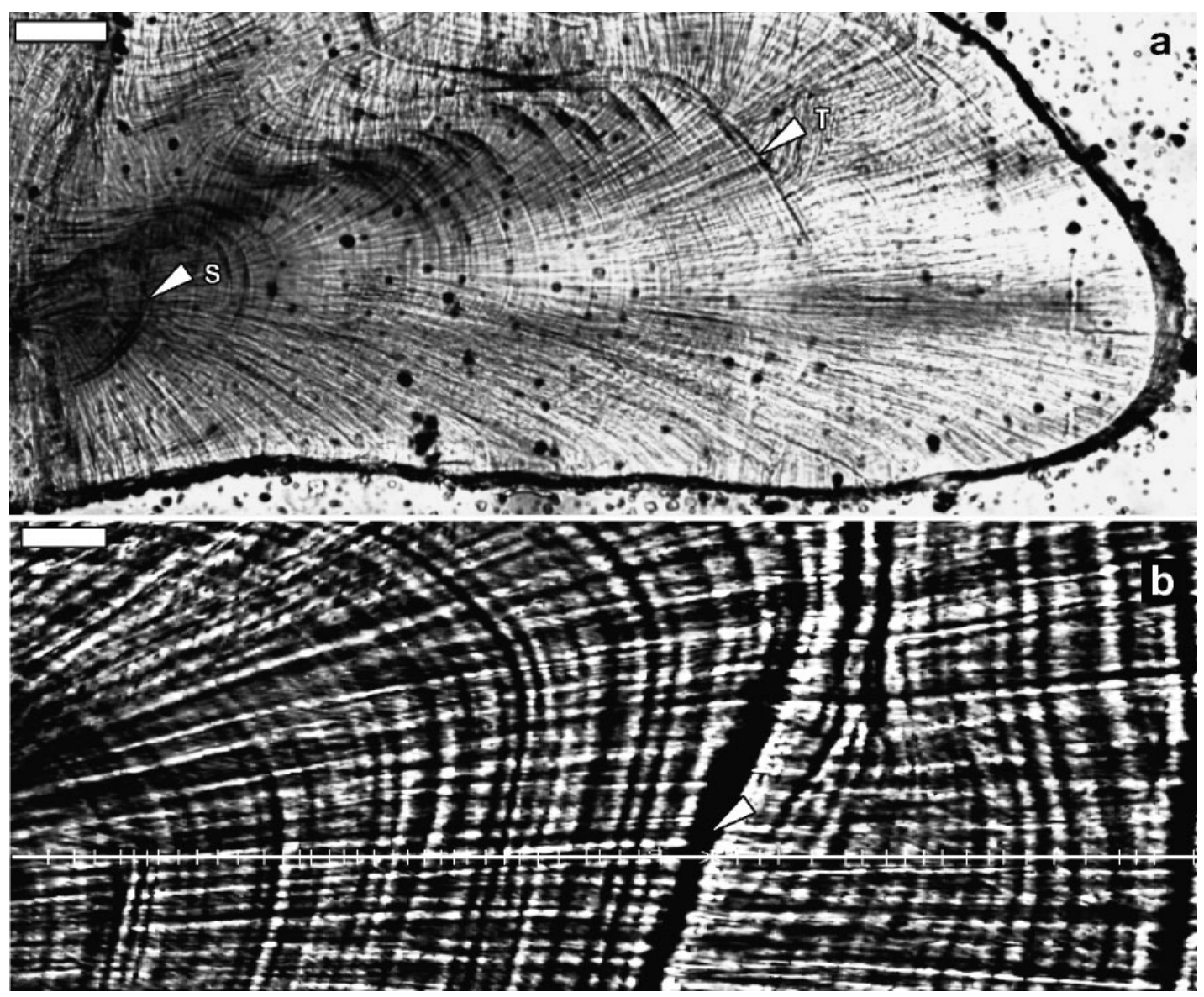

Fig. 6. Parapercis cylindrica. (a) Cross-section of male sagittal otolith showing the check mark associated with sex change (T) and settlement mark (S) $(100 \times$ magnification; scale bar $=50 \mu \mathrm{m})$; (b) daily increments on male sagittal otolith along longest axis in region of increased increment width, and associated check mark (arrowhead) $(400 \times$ magnification; scale bar $=10 \mu m)$

\section{Sex change and early life-history traits}

\section{Sex-change candidature}

The average PLD for Parapercis cylindrica was $31.69 \mathrm{~d}$ $( \pm 1.24 \mathrm{SE})$. Fish that had transformed into males displayed a slightly higher SAS than females of similar size, however this was not significant $\left(F_{1,21}=0.189, \mathrm{p}=\right.$ 0.668). Similarly, the LGR, JGR and FGR of similarsized females and males did not differ (LGR: $F_{1,21}=$ $0.1125, \mathrm{p}=0.740 ;$ JGR: $F_{1,21}=0.9926, \mathrm{p}=0.305$; FGR: $F_{1,21}=2.755, \mathrm{p}=0.1551$ ).

\section{Age at sex change}

There were no significant relationships between the age at which females changed sex and PLD, SAS, LGR, JGR, or FGR $\left(F_{5,7}=0.341, \mathrm{p}=0.873\right)$. PLD was negatively related to age at sex change, with a partial cor- relation coefficient of $-0.012(\mathrm{p}=0.975)$. SAS, LGR, and FGR were all positively related to age at sex change, with partial correlation coefficients of 0.03 $(\mathrm{p}=0.939), 0.062(\mathrm{p}=0.874), 0.177(\mathrm{p}=0.649)$, and $0.233(p=0.547)$ respectively. While all measures were non-significant, female growth rate was the best predictor of age at sex change. It should be noted however that these poor relationships might be due in part to small sample size.

\section{DISCUSSION}

Age-based analysis of growth, demography, and gonad development suggests that Parapercis cylindrica is an annual monandric hermaphrodite in which sex change occurs over a very broad range of ages, but a relatively restricted size range. Neither larval growth history nor growth while in the juvenile or female life stages appeared to strongly influence which individ- 


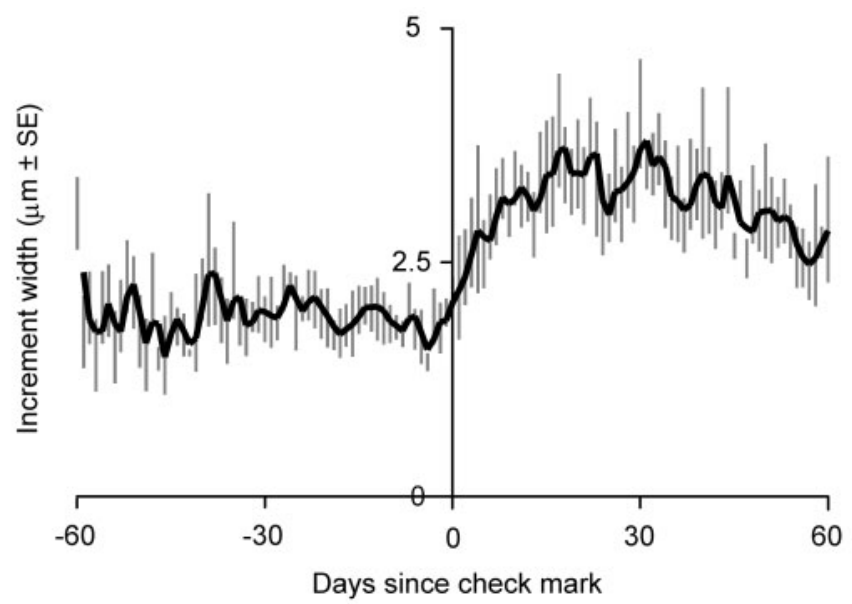

Fig. 7. Parapercis cylindrica. Otolith increment-width profile for males centred at check mark associated with sexual transition. Profile represents moving average plotted every $4 \mathrm{~d}(n=7)$

uals became male, or the age at which the transition occurred. Present evidence suggests that $P$. cylindrica conforms to the 'transitional growth-spurt hypothesis' (Ross 1987) (Fig. 1), with a distinct acceleration in growth occurring at the initiation of sex change. It is this growth-spurt that leads to males monopolising the largest size classes in the population. In contrast, the growth trajectories of males and females were found to diverge well before sex change in the coral trout Plectropomus maculatus (Adams \& Williams 2001), and before female maturation in the freshwater cichlid Cichlasoma citrinellum (Francis \& Barlow 1993). In these species, individuals that establish relatively superior growth early in life are the ones that change sex (Fig. 1).

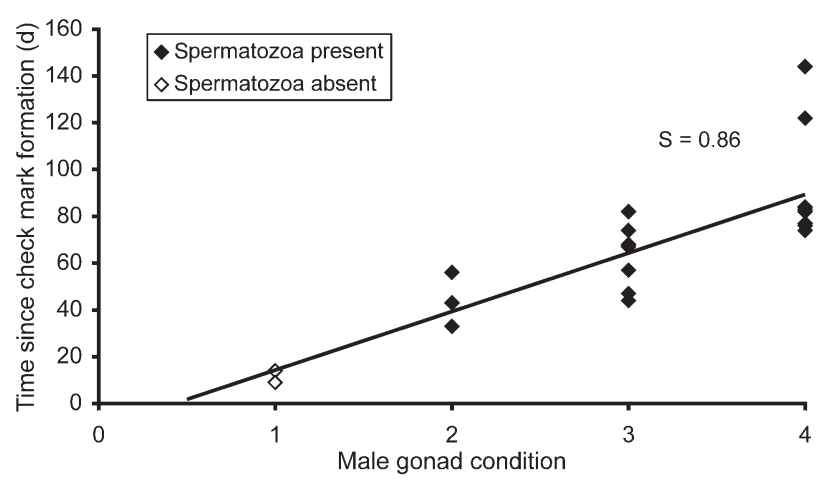

Fig. 8. Parapercis cylindrica. Relationship between number of days between check mark associated with sex change and otolith margin and male gonad status from One Tree Island individuals $(n=20)$. Gonad state $=$ reabsorption stage of the former ovarian lumen, where $1=$ lumen present and $4=$ lumen completely reabsorbed (i.e. absent). $(\bullet)$ spermatozoa present in gonad; $(\diamond)$ spermatozoa absent; S: Spearman's correlation coefficient for rank data
Growth acceleration at sex change may result from a variety of non-exclusive factors. Enhanced growth may be under physiological control and associated with changes in the hormonal profile that occurs as individuals change sex from female to male (Devlin \& Nagahama 2002). This is yet to be investigated. Growth acceleration may also result from the reallocation of energy from reproductive to somatic tissue during sex change. This study has shown that the weight of the gonad relative to body weight declines by an order of magnitude as fish undergo the transition from female to male. Interestingly, it does not appear that enhanced access to food by males is the basis for increased growth. Sano (1993) reported that female Parapercis polyphthalma spent 3-fold more time foraging than males. While the underlying mechanisms are still unclear, we expect accelerated growth at sex change to occur in permanently hierarchical societies where dominant males socially inhibit sex change and subordinate growth through resource- or femaledefence (Brown 1957, Ross 1987).

The lack of a relationship between growth history and the identity of the individuals that change sex, together with the timing of that transition, may be due to the scale of sampling resolution of the present study. Specimens were collected on a large spatial scale (1000s of $\mathrm{m}^{2}$ ) compared to the spatial scale of social units and fish movement (10s of $\mathrm{m}^{2}$ ) (Stroud 1982). However, sex change is dependent on relative rather than absolute size, as indicated by the large size range over which sex change occurred. If the relationship between previous growth history and sex change was investigated for each harem independently, larval, juvenile and female growth histories might have been found to have a greater influence on which individuals change sex and the age at which sex change occurs. Experimental manipulation of pre-transition growth

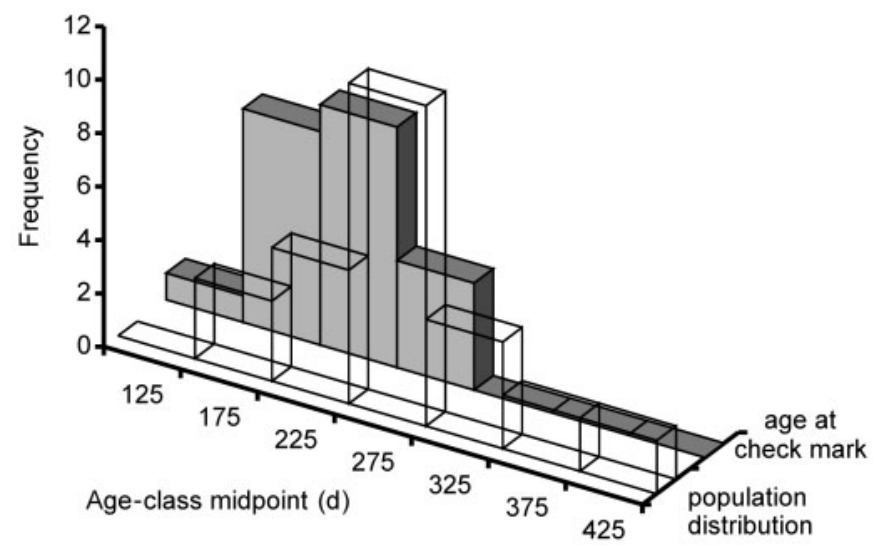

Fig. 9. Parapercis cylindrica. Occurrence-age frequency distribution of male One Tree Island population and location of check mark associated with sexual transition on male otolith cross-sections 
rates (larval, juvenile, female) is required to rigorously address the importance of growth history to the timing and occurrence of sex change. This requires the tracking of growth of newly settled individuals over a range of size-structured social scenarios whilst monitoring the time of sex change.

\section{Otolith and somatic growth}

Parapercis cylindrica is a fast-growing reef fish, and this was reflected in its otolith growth. Maximum otolith radius was linearly related to total fish length, and explained more than $90 \%$ of the variance in fish length for both populations. This relationship was not affected by growth rate and did not differ between populations. The robustness of otolith-somatic relationships is seldom examined, despite the prevalence of studies that use otolith growth to make inferences about somatic growth. Experimental studies have found that otoliths respond conservatively to varying growth conditions, so otolith growth does not necessarily track somatic growth (e.g. Jones \& Brothers 1987, Milicich \& Choat 1992, Molony \& Sheaves 1998). Moreover, for some fish species the relationship between otolith growth and somatic growth is allometric: faster-growing individuals have proportionately smaller otoliths than slower growing individuals of equal sizes (Hare \& Cowen 1995). The lack of any effect of variable growth on otolith-somatic scaling in the present study suggests that otolith width may be used as a proxy for somatic growth throughout the life history of P. cylindrica.

The growth attributes of Parapercis cylindrica are most comparable to tropical gobies that inhabit soft sediments. These display rapid growth, a linear relationship between otolith and somatic growth, high reproductive investment, and longevities spanning no longer than 2.5 yr (Schläppy 1997, Munday \& Jones 1998, Shafer 2000, Kritzer 2002). P. cylindrica had a maximum longevity of $326 \mathrm{~d}$ at Orpheus Island and $411 \mathrm{~d}$ at One Tree Island. However, the present study suggests that $P$. cylindrica differs from the tropical annual gobiids with respect to age- and sex-specific growth rates. Gobiopterus mindanen, Favonigobus reichei, Glossogobius biocellatus (Schläppy 1997), Bathygobius coalitus (Shafer 2000), and Istigobius decoratus (Kritzer 2002) all have linear length-at-age trajectories, with males following the female growth pattern after sex change. In contrast, the von Bertalanffy growth model was found the best descriptor of length-age data for $P$. cylindrica. Curvature of the length-at-age trajectory was particularly pronounced in female growth, and males attained greater lengthsat-age. These growth differences may be explained by this species' social system and the differential benefits of energy allocated to growth and reproduction for each sex (Ghiselin 1969, Warner 1984, 1988). Since $P$. cylindrica forms harems where the male's success in defending females is size-dependent (Stroud 1982, S. Walker unpubl. data), males gain greater fitness advantages than females from energy allocated to somatic growth. In comparison, gobiid species typically form monogamous pairs with low levels of male competition, where the fitness advantages gained from large male size are lower. The hierarchical structure of $P$. cylindrica harems leads to the social mediation of sex change (Stroud 1982). In permanently siteattached haremic species, dominance rank (relative size) rather than absolute size or age, determines sex change (Stroud 1982, Luknesky 1994, Lutnesky \& Kosaki 1995) and also affects subordinate growth (Brown 1957, Borowsky 1978, Ross 1987). These social constraints may explain the broad age-range over which sex change takes place in P. cylindrica and the slowing of growth among old females.

\section{Sexual transition check}

The present study is the first to document the formation of otolith check marks associated with sex change. We identified a distinct check mark in male fish followed by an increase in otolith growth, which coincided with the age-range at which sex change takes place. This was also the period in which female and male growth curves began to separate. Otolith width more that doubled for a period of up to $30 \mathrm{~d}$ after the formation of the check. Detailed examination of the relationship between this otolith check mark and gonad state suggests that the check is formed at the initiation of sex change. The longer the time since formation of the check mark and subsequent accelerated growth, the smaller the former ovarian lumen. Transitional individuals had the largest former ovarian lumens, and a time-since-check-mark formation of less than $20 \mathrm{~d}$ compared to a complete absence of the lumen and a time-since-check-mark formation of at least $70 \mathrm{~d}$ in fully mature males.

Otolith check marks occur almost ubiquitously during settlement (Victor 1982, Pitcher 1988, Wilson \& McCormick 1997, 1999) and during abrupt changes in environmental conditions, such as light, temperature, and feeding regime (e.g. Eckmann \& Rey 1987). Brothers \& McFarland (1981) were the first to note otolith microstructural discontinuities in the French grunt Haemulon flavolineatum that coincided with shifts in habitats use. Given the dramatic shifts in behaviour and physiology associated with sex change, check marks associated with this life-history transition 
are also likely to be commonplace. Unfortunately our ability to detect these changes in the otolith microstructure is likely to be restricted to short-lived species that change sex before the daily increment structure becomes too narrowly spaced to allow accurate resolution.

Parapercis cylindrica is an ideal species with which to examine the importance of growth dynamics to the life-history characteristics of a protogynous fish. The present study provides a foundation, but many issues remain to be resolved. We are currently verifying the transitional check mark by experimental field manipulations of social structures. Once verified, the transitional check will enable the explicit linking of sexual ontogeny, somatic growth and otolith dynamics through field manipulations of harem compositions. This information is crucial to understanding the evolution of the complex social organizations found among tropical fishes.

Acknowledgements. We are grateful to A. Teitelbaum, S. Pausina, M. Depczynski, and the staff of Orpheus Island research station and One Tree Island research station for assistance with fieldwork. J. Ackerman gave valuable advice in otolith preparation and analysis, S. Adams and S. Reilly aided in histological preparation and examination. H. Choat, J. Ackerman, S. Adams, P. Munday, A. Sampy, M. Depczynski and 3 anonymous reviewers provided critical discussion and comments.

\section{LITERATURE CITED}

Adams S, Williams AJ (2001) A preliminary test of the transitional growth spurt hypothesis using the protogynous coral trout Plectropomus maculatus. J Fish Biol 59:183-185

Borowsky R (1978) Social inhibition of maturation in natural populations of Xiphophorus variatus (Pisces: Poeciliidae). Science 201:933-935

Brothers EB, McFarland WN (1981) Correlations between otolith microstructure, growth, and life history transitions in newly recruited French grunts [Haemulon flavolineatum (Desmarest), Haemulidae]. Rapp P-V Réun Cons Int Explor Mer 178:369-374

Brown ME (1957) Experimental studies on growth. In: Brown ME (ed) The physiology of fishes, Vol 1. Academic Press, New York, p 361-400

Campana SE (2001) Accuracy, precision and quality control in age determination, including a review of the use and abuse of age validation methods. J Fish Biol 59:197-242

Choat JH, Axe LM, Lou DC (1996) Growth and longevity in fishes of the family Scaridae. Mar Ecol Prog Ser 145:33-41

Devlin RH, Nagahama Y (2002) Sex determination and sex differentiation in fish: an overview of genetic, physiological, and environmental influences. Aquaculture 208: 191-364

Eckmann R, Rey P (1987) Daily increments on the otoliths of larval and juvenile Coregonus spp. and their modification by environmental factors. Hydrobiologia 148:137-143

Francis RC, Barlow GW (1993) Social control of primary sex differentiation in the Midas cichlid. Proc Natl Acad Sci 90: 10673-10675
Garratt PA, Govender A, Punt AE (1993) Growth acceleration at sex change in the protogynous hermaphrodite Chrysoblephus puniceus (Pisces: Sparidae). S Afr J Mar Sci 13: 187-193

Ghiselin MT (1969) The evolution of hermaphroditism among animals. Q Rev Biol 44:189-208

Hare JA, Cowen RK (1995) Effect of age, growth rate, and ontogeny on the otolith size-fish size relationship in bluefish, Pomatomus saltrix, and the implications for backcalculation of size in fish early life history stages. Can J Fish Aquat Sci 52:1909-1922

Jones C, Brothers EB (1987) Validation of the otolith increment aging technique for striped bass, Morone saxatillis, larvae reared under sub optimal feeding conditions. Fish Bull Fish US 89:611-621

Kritzer JP (2002) Stock structure, mortality and growth of the decorated goby, Istigobius decoratus (Gobiidae), at Lizard Island, Great Barrier Reef. Environ Biol Fish 63:211-216

Lutnesky MMF (1994) Density-dependant protogynous sex change in territorial-haremic fishes: models and evidence. Behav Ecol 5:375-383

Lutnesky MMF, Kosaki RK (1995) Female-female competition in a coral reef fish and a test of the temporal threshold model of polygymous mating. Am Nat 146:832-847

Milicich MJ, Choat JH (1992) Do otoliths record changes in somatic growth rate-conflicting evidence from a laboratory and field study of a temperate reef fish, Parika scaber. Aust J Mar Freshw Res 43:1203-1214

Molony BW, Sheaves MJ (1998) Otolith increment widths and lipid contents during starvation and recovery feeding in adult Ambassis vachelli (Richardson). J Exp Mar Biol Ecol 221:257-276

Munday PL, Jones GP (1998) The ecological implications of small body size among coral-reef fish. Oceanogr Mar Biol Annu Rev 36:373-411

Pitcher CR (1988) Validation of a technique for reconstructing daily patterns in the recruitment of coral reef damselfish. Coral Reefs 7:105-111

Randall JE, Allen GR, Steene RC (1997) Fishes of the Great Barrier Reef and Coral Sea. University of Hawaii, Honolulu

Ross RM (1987) Sex-change linked growth acceleration in a coral-reef fish, Thalassoma duperrey. J Exp Zool 244: $455-461$

Sadovy Y, Shapiro DY (1987) Criteria for the diagnosis of hermaphroditism in fish. Copeia 1987:137-156

Sano M (1993) Foraging activities and diets of males and females in a haremic sandperch (Pisces: Pinguipedidae). Mar Ecol Prog Ser 98:55-59

Schläppy (1997) Patterns of growth, reproduction and survival in gobiid fish: the implications of small body size on life history characteristics. BSc thesis, James Cook University, Townsville

Shafer DJ (2000) Evaluation of periodic and aperiodic otolith structure and somatic-otolith scaling for use in retrospective life history analysis of a tropical marine goby, Bathygobius coalitus. Mar Ecol Prog Ser 199:217-229

Shea BT (1985) Bivariate and multivariate growth allometry: statistical and biological considerations. J Zool Ser A 206 : 367-390

Stroud GJ (1982) The taxonomy and biology of fishes of the genus Parapercis (Teleostei: Mugiloididae) in Great Barrier Reef waters. PhD thesis, James Cook University, Townsville

Victor BC (1982) Daily otolith increments and recruitment in two coral-reef wrasses, Thalassoma bifasciatum and Halichoeres bivittatus. Mar Biol 71:203-208

Vigliola L, Meekan MG (2002) Size at hatching and plank- 
tonic growth determine post-settlement survivorship of a coral reef fish. Oecologia 131:89-93

Warner RR (1984) Mating behavior and hermaphroditism in coral reef fishes. Am Sci 72:128-136

Warner RR (1988) Sex change in fishes: hypotheses, evidence, and objections. Environ Biol Fish 22:81-90

Werner EE, Gilliam JF (1984) The ontogenetic niche and species interactions in size-structured populations. Annu Rev Ecol Syst 15:393-425

Wilson DT, McCormick MI (1997) Spatial and temporal vali-

Editorial responsibility: Otto Kinne (Editor),

Oldendorf/Luhe, Germany dation of settlement-marks in the otoliths of tropical reef fishes. Mar Ecol Prog Ser 153:259-271

Wilson DT, McCormick MI (1999) Microstructure of settlement-marks in the otoliths of tropical reef fishes. Mar Biol 134:29-41

Winsor L (1994) Tissue processing. In: Woods A, Ellis RC (eds) Laboratory histopathology: a complete reference. Churchill Livingston, London

Zar JH (1999) Biostatistical analysis, 4th edn. Prentice-Hall, Upper Saddle River, NJ

Submitted: January 3, 2003; Accepted: September 16, 2003 Proofs received from author(s): January 14, 2004 